\title{
Correlation between ultrasonography measured transcerebellar diameter of foetus with early and late gestational age
}

\author{
Charusmita Agrawal $^{1 *}$, Kamlesh Kumar Agrawal $^{2}$, Sudha Gandhi $^{3}$, Sarita Chaudhary ${ }^{4}$
}

\author{
${ }^{1}$ Department of Obstetrics \& Gynaecology, SMS Medical College, Jaipur, Rajasthan, India \\ ${ }^{2}$ Department of Pediatrics, SMS Medical College, Jaipur, Rajasthan, India \\ ${ }^{3}$ Department of Obstetrics \& Gynaecology, RNT Medical College, Udaipur, Rajasthan, India \\ ${ }^{4}$ Gynaecology Department, Civil Hospital, Gurgaon, Haryana, India
}

Received: 14 October 2015

Accepted: 18 November 2015

\author{
*Correspondence: \\ Dr. Charusmita Agrawal, \\ E-mail: drcharusmita@gmail.com
}

Copyright: () the author(s), publisher and licensee Medip Academy. This is an open-access article distributed under the terms of the Creative Commons Attribution Non-Commercial License, which permits unrestricted non-commercial use, distribution, and reproduction in any medium, provided the original work is properly cited.

\section{ABSTRACT}

Background: Traditionally, the gestational age of the foetus is determined from the date of the last menstrual period. Prediction of gestational age (GA) based on sonographic foetal parameters is perhaps the cornerstone in modern obstetrics and continues to remain an important component in the management of pregnancies with foetuses who have growth disturbances. The objective of the study was to study the correlation between foetal transcerebellar diameter (TCD) and pregnancy age, addressing early and late gestation periods.

Methods: This prospective observational study was conducted in the 100 pregnant women. Ultrasound examination for TCD and gestation age was done between 20-28 weeks of gestation and between 30-36 weeks of gestation. For the measurement of TCD transverse view of the foetal intracranium was obtained. Statistical analysis was performed using suitable tests.

Results: Mean age of the women was $24.82+3.31$ and $85 \%$ women were in age group 21-30. The mean TCD in early gestational age i.e. $20-28$ weeks was $24.7 \pm 3.86$ and in late gestational age i.e. 30-36 weeks was $39.31 \pm 2.51$. Median TCD increases from $20.35 \mathrm{~mm}$ at 20 weeks to $41.7 \mathrm{~mm}$ at 36 weeks of gestation. The correlation coefficient between gestational age and TCD was 0.971 , which indicated high degree of relation with $\mathrm{p}$ value $<0.0001$.

Conclusions: This study shows linear relationship between TCD and gestational age at 20-28 weeks \& 30-36 weeks. So, TCD is a reliable method of gestational age determination in early as well as in late pregnancy.

Keywords: Transcerebellar diameter, Gestational age, Foetus, Menstrual period

\section{INTRODUCTION}

Traditionally, the gestational age of the foetus is determined from the date of the last menstrual period. Only $71 \%$ women can accurately recall their date of last menstrual period. ${ }^{1}$ Even when the date of last menstrual period can be recalled reliably, the gestational age so determined is not always reliable. This may be because of irregular cycles, lactation, recent use of hormonal contraceptives, intrauterine devices, bleeding in first trimesters, hormone therapy etc. Therefore, even in women with regular menstrual cycles, ultrasound dating of pregnancy provides a more accurate estimation of gestational age than by menstrual history. ${ }^{2}$ Prediction of gestational age (GA) based on sonographic foetal parameters is perhaps the cornerstone in modern obstetrics and continues to remain an important component in the management of pregnancies with foetuses who have growth disturbances. ${ }^{3}$ Prenatal Ultrasonography provides an opportunity to more accurately assess foetal growth, as it is highly reliable and reproducible. Ultrasound biometry of the foetus is now the gold standard for assessing the foetal growth. ${ }^{4}$ Transcerebellar diameter (TCD) is one such foetal parameter that has remained consistently superior in predicting GA and foetal growth in both singleton and twin gestations. ${ }^{5-7}$ It is therefore an organ that can provide information on the prediction of gestational age during 
the entire pregnancy. Although there are ultrasound studies on the correlation between the Transverse cerebellar diameter (TCD) in foetuses and gestational age, most studies address the third trimester of pregnancy. ${ }^{5,8-11}$ It is therefore important to study the correlation between foetal TCD and pregnancy age, addressing early and late gestation periods. So, this study was planned to evaluate the role of foetal transcerebellar diameter in predicting gestational age.

\section{METHODS}

This prospective observational study was conducted in the pregnant women attending the antenatal clinic of a tertiary care teaching hospital for a period of one and a half year. A total of 100 pregnant women were recruited in this study after taking approval from Institutional Ethics Committee. Written informed consent was taken from the patients. All singleton pregnancies women between 20 to 36 weeks of gestational age, pregnant women with confirmed gestational age (having regular menstrual history and knowing confirm date of last menstrual period) were include in the study. The exclusion criteria included uncertain date of last menstrual period (LMP), multiple pregnancies and major structural anomaly identified with ultrasound.

Women were studied on two antenatal visits. During each visit thorough history, clinical and ultrasound examinations were performed. First ultrasound examination was done between 20-28 weeks of gestation and second ultrasound examination was done between 30-36 weeks of gestation. All ultrasonic examinations were performed with an ALOKA [SSD 4000 SV] ultrasound machine with a $2.5-6 \mathrm{MHz}$ convex transducer. Electronic calipers were used and all measurements were taken in millimeters. During each ultrasound examination, in addition to various routine sonographic foetal biometers like BPD, HC, FL, AC, the transverse cerebellar diameter (TCD) was also measured.

The transverse cerebellar diameter was measured by the method as described by Goldstein et al. ${ }^{12}$ For the measurement of TCD transverse view of the fetal intracranium was obtained. The landmarks of the thalami, cavum, septum pallucidum and third ventricle were identified followed by slight rotation of the transducer below the thalamic plane to view the butterfly like structure (cerebellum) in the posterior cranial fossa. The measurement was obtained by placing electronic calipers of the ultrasound machine at the outer to outer margins of the cerebellum.

\section{Statistical analysis}

Mean and standard deviation of TCD was determined at each week of gestation, in addition the $5^{\text {th }}, 50^{\text {th }} 90^{\text {th }}$ and $95^{\text {th }}$ percentiles were also calculated. Statistical analysis was performed using Student's ' $t$ ' test, Analysis of Variance (ANOVA), Pearson's Correlation, Regression analysis and Chi-Square Test wherever applicable. A "P" value of $<0.05$ was considered to be statistically significant.

\section{RESULTS}

Table 1: Mean TCD at 20-28 and 30-36 weeks of gestation.

\begin{tabular}{|ll|}
\hline & MEAN \pm SD \\
\hline TCD AT 20-28 Weeks & $24.7 \pm 3.86$ \\
\hline TCD AT 30-36 Weeks & $39.31 \pm 2.51$ \\
\hline
\end{tabular}

Table 2: Transverse cerebellar diameter (TCD) percentiles (5th, 50th and 95th) relative to gestational age (weeks).

\begin{tabular}{|llll|}
\hline Gestational & \multicolumn{3}{l|}{ TCD Percentiles $(\mathbf{m m})$} \\
\hline 20 & $5^{\text {th }}$ & $50^{\text {th }}$ & $95^{\text {th }}$ \\
\hline 21 & 18.56 & 20.35 & 22.19 \\
\hline 22 & 19.6 & 21.15 & 23.22 \\
\hline 23 & 20.05 & 21.85 & 24.75 \\
\hline 24 & 21.35 & 23.6 & 25.2 \\
\hline 25 & 22.22 & 24.1 & 26.54 \\
\hline 26 & 24.17 & 26.6 & 27 \\
\hline 27 & 27.15 & 28.6 & 31.6 \\
\hline 28 & 27.28 & 30.2 & 31.35 \\
\hline 30 & 30.32 & 31 & 36.47 \\
\hline 31 & 32.5 & 34.3 & 37.37 \\
\hline 32 & 34.94 & 36.5 & 40.8 \\
\hline 33 & 35.4 & 38.4 & 42 \\
\hline 34 & 34.85 & 38.7 & 41.56 \\
\hline 35 & 38.02 & 40.7 & 41.3 \\
\hline 36 & 38.27 & 42 & 43.36 \\
\hline
\end{tabular}

The study included 100 pregnant women who attended the antenatal clinic. Mean age of the women was $24.82+3.31$ and $85 \%$ women were in age group 21-30.

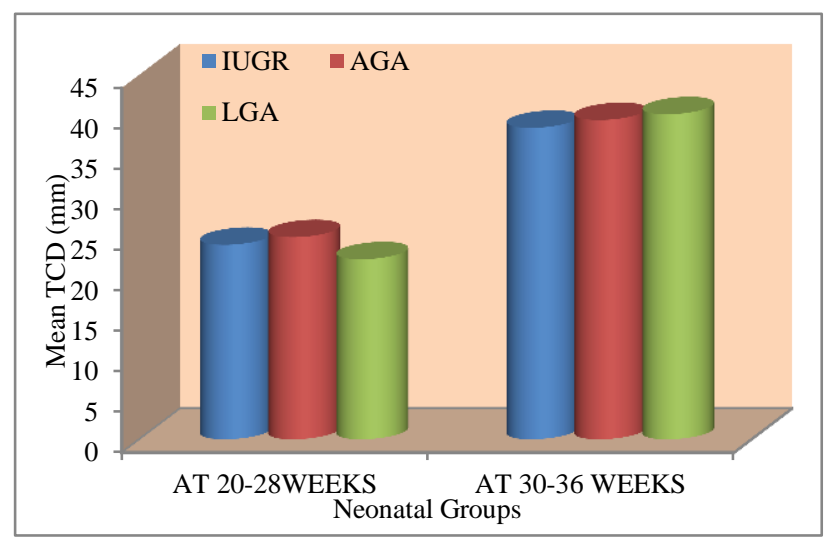

Figure 1: Mean TCD at 20-28 and 30-36 Weeks in neonates of different groups. 
The mean TCD in early gestational age i.e. 20-28 weeks was $24.7 \pm 3.86$ and in late gestational age i.e. 30-36 weeks was $39.31 \pm 2.51$. At $20-28$ weeks of gestational age minimum TCD was $18 \mathrm{~mm}$ and maximum TCD was $38.6 \mathrm{~mm}$ and at 30-36 weeks it was $34 \mathrm{~mm}$ and $48.2 \mathrm{~mm}$ respectively (Table 1).

There was no statistically significant difference ( $\mathrm{P}$ value $>0.05$ ) in mean TCD at 20-28 weeks as well as in mean TCD at 30-36 weeks in growth restricted (IUGR) neonates, appropriately grown neonates (AGA) and large for gestational age (LGA) neonates (Figure 1).

Median TCD (50th percentile) increases from $20.35 \mathrm{~mm}$ at 20 weeks to $41.7 \mathrm{~mm}$ at 36 weeks of gestation. The 5th and 95 th percentiles at 20 weeks were 18.56 and 22.19 $\mathrm{mm}$ and at 36 weeks these were 39.7 and $46.97 \mathrm{~mm}$ respectively. The inference shows that the normal foetal TCD exhibit a more than two fold increase in size between 20 to 36 weeks of gestation (Table 2).

The scatter diagram between gestational age and TCD in weeks shows linear relationship between gestational age and TCD, which was statistically significant as R2 $=0.942$. The correlation coefficient between gestational age and TCD was 0.971, which was statistically significant ( $\mathrm{p}$ value $<0.0001)$ and indicates high degree of correlation (Figure 3).

\section{DISCUSSION}

Cerebellum lies in the posterior cranial fossa, surrounded by the dense petrous ridges and occipital bone so it can withstand deformation by extrinsic pressure better than the parietal bones. Prediction of gestational age is important for the management of the complicated pregnancies. TCD is considered as important parameter for estimation of gestational age.

Table 3: Comparison of present study with previous studies for relationship between TCD and gestational age.

\begin{tabular}{|llll|}
\hline Study & $\begin{array}{l}\text { Correlation } \\
\text { Coefficient } \\
(\mathbf{r})\end{array}$ & $\mathbf{R}^{2}$ & P value \\
\hline Present study & 0.971 & 0.942 & $<0.0001$ \\
\hline $\begin{array}{l}\text { Goldstein I et al } \\
1987^{12}\end{array}$ & - & 0.948 & $<0.001$ \\
\hline Guan et al 1992 & 0.996 & - & $<0.0005$ \\
\hline $\begin{array}{l}\text { Vinkesteijn ASM } \\
\text { et al 2000 }\end{array}$ & - & 0.96 & $<0.0001$ \\
\hline $\begin{array}{l}\text { Araujo J et al } \\
\text { 2008 }\end{array}$ & 0.98 & 0.969 & $<0.0001$ \\
\hline $\begin{array}{l}\text { Goel P et al } \\
2010^{13}\end{array}$ & 0.991 & - & $<0.0001$ \\
\hline $\begin{array}{l}\text { Das Gupta A et al } \\
2012^{14}\end{array}$ & 0.946 & 0.896 & $<0.0001$ \\
\hline
\end{tabular}

In this study mean age of the women was 24.82. Another study done by Chavez et al, the mean maternal age was 30 years. $^{3}$ This difference in age may be explained by the fact that in India there is a trend of early marriage and pregnancy at an early age.

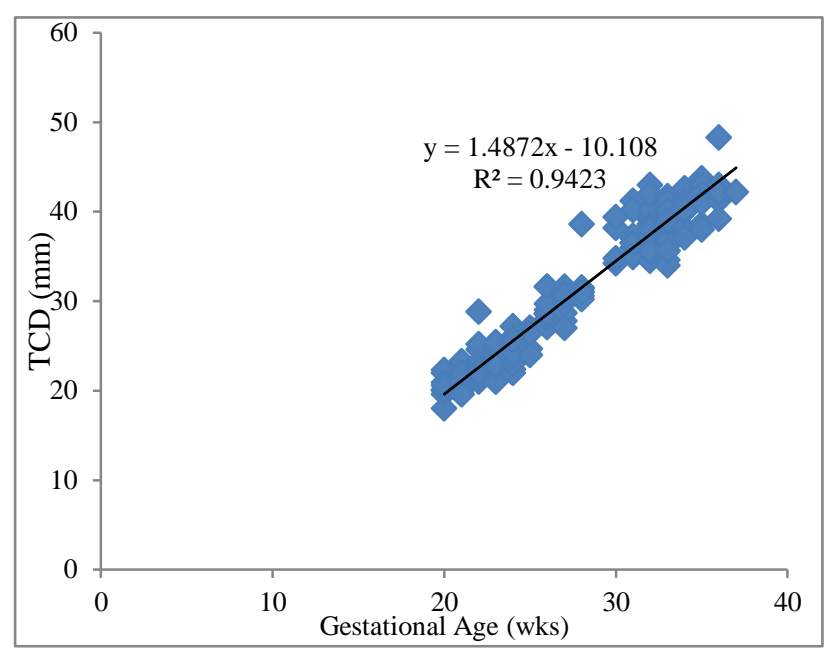

Figure 2: Relationship between TCD and gestational age.

The mean TCD in early gestational age i.e. 20-28 weeks is $24.7 \pm 3.86$ and in late gestational age i.e. $30-36$ weeks was $39.31 \pm 2.51$. In a similar study done by Goel $\mathrm{P}$ et al, the mean TCD at 21-30 weeks of gestational age was $26.63 \mathrm{~mm}$ and at $31-40$ weeks of gestational age was $40.73 \mathrm{~mm}$. The minimum and maximum TCD at 21-30 weeks was $18.40 \mathrm{~mm}$ and $35 \mathrm{~mm}$ and at 31-40 weeks it was $36 \mathrm{~mm}$ and $48.4 \mathrm{~mm}$ respectively. ${ }^{13}$ In another study done by Das gupta et al, the mean TCD during 21-27 weeks was $23.2 \mathrm{~mm}$ with minimum and maximum TCD $20 \mathrm{~mm}$ and $28 \mathrm{~mm}$ respectively, and during 28-34 weeks the mean TCD was $30.6 \mathrm{~mm}$, minimum and maximum TCD were $24 \& 35 \mathrm{~mm}$ respectively. During 35-40 weeks the mean, minimum and maximum TCD were respectively $35.2 \mathrm{~mm}, 30 \mathrm{~mm}$ and $40 \mathrm{~mm} .{ }^{14}$ Reece EA et al has stated that the growth of the transverse cerebellar diameter is unaffected by intrauterine growth retardation. ${ }^{15}$ Strizhova NV et al measured the TCD in normal and growth retarded foetuses and concluded that TCD of small-for gestational age did not much differ from that in the normal reference group. ${ }^{16}$ Goldstein I et al in their study also concluded that there was no significant difference between growth of the transverse cerebellar diameter in the appropriately grown and growth restricted children. ${ }^{17}$ These data confirm the relative preservation of normal cerebellar growth in growth restricted foetuses.

In our study the normal foetal TCD exhibit a more than two fold increase in size between 20 to 36 weeks of gestation. Similar results were obtained by Vinkesteijn ASM et al, in which median TCD $\left(50^{\text {th }}\right.$ percentile $)$ increases more than two fold during second half of pregnancy. They obtained median TCD of $17.5 \mathrm{~mm}$ at 17 
weeks which increased to $45.2 \mathrm{~mm}$ at 34 weeks of gestation. ${ }^{9}$ Dasgupta $A$ et al also calculated the percentiles $\left(5^{\text {th }}, 50^{\text {th }}\right.$ and $\left.95^{\text {th }}\right)$ of $\mathrm{TCD}$ relative to gestational age, which are comparable to our study. ${ }^{14}$

Our study shows linear relationship between gestational age and TCD, which is statistically significant $\left(\mathrm{R}^{2}\right.$ $=0.942, \mathrm{P}$ value $=0.0001)$. Similar observations were obtained in other studies and their results are also comparable to our study as shown in the Table 3.

\section{CONCLUSION}

In this study, the relationship was established between TCD and gestational age 20-28 weeks \& 30-36 weeks. This study shows linear relationship between gestational age and TCD. So, transcerebellar diameter is a reliable method of gestational age determination in early as well as in late pregnancy.

\section{Conflict of interest: None declared}

Ethical approval: The study was approved by the Institutional Ethics Committee of Government Medical College, Udaipur, India

\section{REFERENCES}

1. Andersen HF, Johnson TR, Flora JD, Barclay ML. Gestational age assessment. II. Prediction from combined clinical observations. Am J Obstet Gynecol. 1981;140(7):770-4.

2. Mongelli M, Wilcox M, Gardosi J. Estimating the date of confinement: ultrasonographic biometry versus certain menstrual dates. Am J Obstet Gynecol. 1996;174:278-81.

3. Chavez MR, Ananth CV, Smulian JC. Fetal transcerebellar diameter measurement for prediction of gestational age at extremes of fetal growth. J Ultrasound Med. 2007;26(9):1167-71.

4. Peleg D, Kennedy CM, Hunter SK. Intrauterine growth restriction: identification and management. Am Fam Physician. 1998;58(2):453-60.

5. Chavez MR, Ananth CV, Smulian JC, Lashley S, Kontopoulos EV, Anthony $\mathrm{M}$ et al. Fetal transcerebellar diameter nomogram in singleton gestations with special emphasis in the third trimester: a comparison with previously published nomograms. Am J Obstet Gynecol. 2003;189(4):1021-5.

6. Chavez MR, Ananth CV, Smulian JC, Yeo L, Oyelese Y, Vintzileos AM. Fetal transcerebellar diameter measurement with particular emphasis in the third trimester: a reliable predictor of gestational age. Am J Obstet Gynecol. 2004;191:979-84.
7. Chavez MR, Ananth CV, Smulian JC, Yeo L, Karminsky LM, Vintzelios AM. Fetal transcerebellar diameter measurement for prediction of gestational age in twins. Am J Obstet Gynecol. 2006;195:1596600.

8. Chang $\mathrm{CH}$, Chang FM, Yu CH, Ko HC, Chen HY. Three-dimensional ultrasound in the assessment of fetal cerebellar transverse and antero-posterior diameters. Ultrasound Med Biol. 2000;26:175-82.

9. Vinkesteijn ASM, Mulder PGH, Wladimiroff JW. Fetal transverse cerebellar diameter measurements in normal and reduced fetal growth. Ultrasound Obstet Gynecol. 2000;15:47-51.

10. Araujo EJ, Pires CR, Nardozza, LMM, Filho HAG, Moron AF. Correlation of the fetal cerebellar volume with other fetal growth indices by three-dimensional ultrasound. J Mater Fetal Neonatal Med. 2007;20:581-7.

11. Malik G, Waqar F, Zaidi H. Determination of gestational age by transverse cerebellar diameter in third trimester of pregnancy. J Coll Phys Surg Pak. 2006;16:249-52.

12. Goldstein I, Reece A, Pilu G, Boricelli L, Hobbins J. Cerebellar measurements with ultrasonography in the evaluation of fetal growth and development. Am J Obstet Gynecol. 1987;156:1065-9.

13. Goel P, Single M, Ghai R, Jain S, Budhiraja V, Babu CSR. Transverse Cerebellar Diameter - A Marker for Estimation of Gestational Age. J Anat Soc India. 2010;59(2):158-61.

14. Dasgupta A, Benerjee A, Rammurthy N, Revati P, Jose J, Karak P. Gestational Age Estimation Using Transcerebellar Diameter With Grading of Fetal Cerebellar Growth. National Journal of Clinical Anatomy. 2012;1(3):115-20.

15. Reece AE, Goldstein I, Pilu G, Hobbins JC. Fetal cerebellar growth unaffected by intrauterine growth retardation: a new parameter for prenatal diagnosis. Am J Obstet Gynecol. 1987;157:632-8.

16. Strizhova NV, Elamin HY, Bokin IS. The ultrasound diagnosis of intrauterine fetal growth retardation. Akush Ginekol (Mosk). 1992;(8-12):30-2.

17. Goldstein I, Reece EA. Cerebellar growth in normal and growth restricted fetuses of multiple gestations. Am J Obstet Gynaecol. 1995;173(4):1343-8.

18. Guan B, Xue Zhi ZY. Surveillance of fetal growth and fetal cerebellar transverse diameter by ultrasonographic measurement. 1992;72(2):65-7.

Cite this article as: Agrawal C, Agrawal KK, Gandhi S, Chaudhary S. Correlation between ultrasonography measured transcerebellar diameter of foetus with early and late gestational age. Int J Reprod Contracept Obstet Gynecol 2015;4:2010-3. 